\title{
Progression and Outcome of Patients in a Canadian Dementia Clinic
}

\author{
David B. Hogan, Daniel E. Thierer, Erika M. Ebly and Irma M. Parhad
}

\begin{abstract}
Five hundred and fifty-three patients were referred to a Canadian dementia clinic for standardized evaluation. The majority $(83.5 \%$ ) had a dementia with Alzheimer's disease (AD) accounting for $89 \%$ of dementias. Patients with probable AD who were followed for five years had variable rates of progression, increased mortality $(37.1 \%, 2.5$ times the expected rate) and a high rate of institutionalization (79\%). Simple demographic (age) and social factors (marital status) were strong predictors for institutionalization. It was extremely difficult at presentation to predict the rate of progression. The prevalence of AD in autopsied cases was $62.5 \%$. Clinic patients were younger, had milder dementias, and were more likely to have AD than patients identified in the course of a contemporaneous population-based dementia prevalence study.
\end{abstract}

\begin{abstract}
Résumé: Progression et devenir des patients référés dans une clinique canadienne de démence. Cinq cent cinquante-trois patients ont été référés à une clinique canadienne de démence pour subir une évaluation standardisée. La majorité $(83.5 \%)$ avaient une démence et $89 \%$ des démences étaient dues à la maladie d'Alzheimer. Les patients avec maladie d'Alheimer probable, qui ont été suivis pendant cinq ans, avaient des taux variables de progression, une mortalité plus élevée ( $37.1 \%$, soit 2.5 fois le taux attendu) et un taux élevé d'institutionnalisation (79\%). Des facteurs démographiques (l'âge) et sociaux (l'état matrimonial) simples étaient des prédicteurs puissants de l'institutionnalisation. Il était extrêmement difficile à l'évaluation initiale de prédire le taux de progression. La prévalence de la maladie d'Alzheimer chez les cas ayant subi une autopsie était de $62.5 \%$. Les patients de la clinique étaient plus jeunes, avaient une démence moins sévère et étaient plus susceptibles d'avoir la maladie d’Alzheimer que les patients identifiés lors d'une étude de population concomitante étudiant la prévalence de la démence.
\end{abstract}

Can. J. Neurol. Sci. 1994; 21: 331-338

Specialized ambulatory care clinics for the assessment and management of patients with suspected dementia are a recent development. These clinics generally assess patients upon referral from physicians and provide diagnostic opinion, advice on management, longitudinal follow-up, and/or conduct clinical dementia research such as drug trials. Patients undergo a standardized assessment by trained, experienced staff who utilize accepted, validated criteria to make diagnoses. Within the setting of these clinics various health care disciplines can be brought together to focus their expertise on the multifaceted problem of dementia. There is some support that this multidisciplinary approach provides greater diagnostic accuracy than traditional monodisciplinary assessments.' Published reports indicate that most referred patients do have a dementia with Alzheimer's Disease (AD) being the single most common etiology. ${ }^{2-8}$ The typical referred patient is a female in her early seventies residing in the general community. ${ }^{2-8}$ At the time of the initial assessment, patients had experienced cognitive symptoms (usually memory loss) for two to four years. ${ }^{2-8}$ To date no studies have been published describing the characteristics of patients seen in Canadian dementia clinics.

An unanswered question is whether the description of patients seen in these clinics can be extended to all patients with dementia. ${ }^{9}$ Selection bias may influence the characteristics of these populations to an important degree making them nonrepresentative of the dementia population as a whole. It would be useful to compare the characteristics of a large dementia clinic population to those of a contemporaneous population-based study of dementia conducted in the same geographic area in order to explore this issue.

Progression of dementia, in particular AD, and its prediction, is an important area under active investigation. There is no consensus on the best instrument to monitor progression. Efforts are being directed on developing new scales and evaluating which of currently available instruments are most sensitive to clinically significant disease progression while not manifesting large inherent variability. ${ }^{10}$ There is acknowledged heterogeneity in the progression of $\mathrm{AD}$. There is also growing acceptance that progression is not uniform throughout the course of the illness for an individual." A trilinear model where there is an initial period of stability followed by a period of decline and then a

From the Departments of Medicine. Clinical Neurosciences and Pathology, University of Calgary, Calgary

RECEIVED FEBRUARY 10, 1994. ACCEPTED IN FINAL FORM MAY 9. 1994

Reprint requests 10: David B. Hogan, M.D., University of Calgary, Health Sciences Centre, 3330 Hospital Drive N.W., Calgary, Alberta. Canada T2N 4NI 
final period of stability has been found to provide a more accurate estimate of average rate of change than a linear model. ${ }^{12}$ Reported risk factors for rapid progression include greater (and also lesser) degrees of impairment when first assessed, more profound language impairment, greater degrees of impairment in executive cognitive functioning, extrapyramidal signs, myoclonus, muscular rigidity, apraxia, behavioral/psychiatric problems (i.e., paranoid delusions and hallucinations), younger age at onset, longer duration of symptoms, female gender, and certain electroencephalography (EEG) characteristics. ${ }^{2.11 .13-22}$ While scales incorporating functional skills are felt to be more appropriate for longitudinal studies, the Mini-Mental State Examination (MMS) has been used to follow patients with dementia and has been shown to decline by two to five points per year. ${ }^{23}$

Hard endpoints in the progression of AD are mortality and institutionalization within a long-term care facility (LTCF). The literature consistently shows an increased mortality rate for patients with $\mathrm{AD}$ when compared to appropriate, matched control groups. ${ }^{14,15,24-31}$ Five-year mortality rates range from 42 to $81 \%$ with the risk of dying being 1.23 to 3.5 times the expected rate. ${ }^{14,15.24 .31}$ Risk factors for dying include increased dementia severity, behavioral problems, psychotic features, falls, increased age (though some studies show that lower ages carry an increased relative risk), more rapid disease progression, caregiver psychological morbidity, degree of cortical atrophy on Computerized Tomography (CT), depressive features, increased disease duration, EEG abnormalities, language impairments, hypertension, male gender, greater physical disability/dependency, and apathy. ${ }^{15,16,24,25,29,31-33}$ Increased disease severity has been the most consistent association. Institutionalization identifies the point where patients become dependent for the safe performance of activities of daily living and the support they have in the community cannot deal with these needs. Five-year institutionalization rates for $\mathrm{AD}$ range from 75 to $86 \% .^{10.34 .35}$ Reported risk factors include increased disease severity, rapid disease progression, greater functional dependency (e.g., the presence of incontinence), impaired ambulation, behavioral problems (e.g., irritability, sleep disturbances, wandering, agitation), and various care-giver factors. ${ }^{10,34,35}$

The Dementia Research Clinic (DRC) of the University of Calgary was established in 1985. In this paper we will describe the characteristics of patients sequentially referred to the Clinic since its founding. The characteristics of clinic patients were compared with results from the Canadian Study of Health and Aging, a population-based survey of dementia in the elderly 65 and over ${ }^{36}$ We will report on the rate of progression as defined by changes in MMS scores and its prediction for patients diagnosed as having Probable AD. Finally, we will provide the first Canadian data on five-year mortality and institutionalization rates for patients with Probable AD referred to a dementia clinic.

\section{Methods}

The DRC of the University of Calgary is an ambulatory care clinic of the Department of Clinical Neurosciences. Members of the Clinic include neurologists, specialists in geriatric medicine, psychiatrists, neuropsychologists, and nurses, all of whom participate in the assessment of referred patients. Five hundred and fifty three patients were evaluated in the Clinic for cognitive concerns or related issues (e.g., strong family history of a dementing illness in an individual with apparently normal cognition) since 1985. Patients were only seen upon referral from a physician. At the time of referral, $83.4 \%$ of patients were residing in the general community.

All patients were seen initially by a neurologist or a specialist in geriatric medicine. They underwent a standardized assessment which included a semistructured medical and neurological history, a general screening physical examination, a standardized, detailed neurological examination, a MMS Examination, ${ }^{37}$ Blessed-Roth Dementia Scale (DS), ${ }^{38}$ the modified Blessed Dementia Scale (MDS), ${ }^{39}$ the Hachinski Ischemic Scale (HIS), ${ }^{40}$ and select laboratory investigations (Complete Blood Count, Erythrocyte Sedimentation Rate (ESR), electrolytes, creatinine, urea, random blood glucose, Thyroid Stimulating Hormone (TSH), liver enzymes, vitamin B 12 level, Red Blood Cell and serum folate levels, electrocardiogram, chest radiograph, and an unenhanced CT of the head). The history was obtained whenever possible from both the patient and another individual who knew the patient well (termed the informant). The onset and progression of cognitive, functional and behavioral symptoms was recorded.

The MMS examination is a test of general cognitive functioning which includes orientation, memory, language, speech, and praxis. ${ }^{37}$ The DS, the MDS, and information about behavioral concerns was obtained preferably from the informant. The DS is a quantifying measure of functional (i.e., activities of daily living) and behavioral symptoms of dementia. The DS score can range from 0 to 28 , with higher scores representing greater incapacity. The DS has a 0.80 correlation with the MMS. ${ }^{41}$ The MDS, which ranges from 0-17 with higher scores representing greater incapacity, was derived from the DS by the Consortium to Establish a Registry for Alzheimer's Disease (CERAD) to evaluate activities of daily living. ${ }^{42}$ We used the MDS as a summary measure of self-care and functional abilities. The HIS examines a variety of factors which are felt to be useful in predicting the likelihood of a Vascular Dementia ${ }^{40}$ and a high HIS value supports the presence of vascular disease. The neuropsychological battery of the CERAD was administered by a trained nurse on all patients who scored 15 or greater on the MMS. ${ }^{39}$ In addition to the MMS, the individual tests included in this battery were Verbal Fluency (animal category), Boston Naming Test (modified), Word List Memory, Constructional Praxis, Word List Recall, and Word List Recognition. Staff were trained to administer their respective assessments in a standardized manner. The CT scans were read by one experienced neuroradiologist who gave a perceptual grading ${ }^{43}$ for cerebral atrophy and ventricular dilatation which, if present, were graded mild, moderate, and severe. Select patients were referred for detailed psychiatric or neuropsychology assessments.

The criteria of the Diagnostic and Statistical Manual of Mental Disorders. III and IIIR were used for the diagnosis of dementia and vascular dementia. ${ }^{44,45}$ NINCDS-ADRDA criteria were used for the diagnosis of Probable and Possible AD. ${ }^{46}$ Patients with cognitive impairment who did not fulfill criteria for the diagnosis of a dementia were classified as "Cognitive Impairment No Dementia" (CIND). A consensus diagnosis utilizing the collected data and the above noted criteria was reached at regularly scheduled case conferences. All members of the Clinic were invited to attend and participate at these conferences. Most diagnoses were made after the patient's first visit and review of laboratory data though diagnoses could be subsequently changed in light of new information. 
Patients were requested to return at six to twelve month intervals in the Clinic until they died or were institutionalized. Reassessments included MMS examinations. A Progression Index (PI) using MMS scores was calculated for patients with Probable AD in two ways. A retrospective index was calculated using the following formula: (30 - MMS at first visit to Clinic)/ duration of symptoms in years. A prospective index was obtained on patients seen on at least two occasions at least six months apart $(n=135)$ using the following formula: (MMS score when first seen - MMS score when last seen)/ time in years between first and last visit. The average prospective PI was a decline of 3.62. Based on this figure and our review of the literature which suggested an average annual decline of MMS scores of two to five points, ${ }^{23}$ we defined typical or average progression of Probable AD in our Clinic population as a yearly decline of 1.01 to 4.99 points in the MMS. "Slowly Progressive" disease was defined as a MMS decline of no more than one point or an increase in the MMS score. "Rapidly Progressive" cases were defined as a decline of five or more points per year in their MMS scores. Twenty-two percent of patients with Probable AD were found to be Slowly Progressive, $28 \%$ were Rapidly Progressive and the remainder $(50 \%)$ had what we termed "Typically Progressive" disease.

All patients were followed to determine when they were institutionalized and when they died. After institutionalization, regular follow-up phone calls were made until death occurred. Five-year survival and institutionalization rates will be presented on those patients with a diagnosis of Probable AD who were followed for at least five years $(n=62)$. The expected survival rates for an age and gender matched group was estimated using published life-tables for Alberta. ${ }^{47}$ It was the standard practice of the Clinic to request an autopsy which included detailed neuropathologic examination utilizing accepted diagnostic criteria on all patients who died. The autopsy rate for the Clinic was $41 \%$ (40 of 97 deaths) during the time period of this report. There were no major differences in clinical diagnoses between those autopsied and those not autopsied.

Calgary was one of the eighteen centres across Canada included in The Canadian Study of Health and Aging (CSHA), a national prevalence study of dementia in those 65 years of age and older. The study centres were grouped into five geographic regions: British Columbia, the Prairies (which included Calgary, Edmonton, Saskatoon, Winnipeg as study centres), Ontario, Quebec, and the Atlantic region. Regional (Prairie) and national data on the demographics of dementia sufferers, duration of symptoms, dementia severity, and the relative proportions of the main types of dementia encountered were compared to the characteristics of our Clinic population. Specific CSHA data from Calgary was not presented as the study was not designed to provide reliable prevalence data for individual communities. Review of the Calgary data showed that it was consistent with the national and the Prairie regional data. In the CSHA, a Modified Mini-Mental (3MS) State examination ${ }^{48}$ was used rather than the MMS. MMS scores were derived from the 3MS scores using a validated formula. ${ }^{49}$

Clinical, laboratory, and diagnostic data obtained at the time of the initial assessment were systematically recorded on standardized forms and routinely entered in a computerized database using DBASE IV software (Ashton-Tate, Torrance, CA). Followup data entered were any subsequent MMS scores, subsequent DS scores, subsequent MDS scores, date of institutionalization, and date of death. Mean values are reported with standard error of the mean (S.E.M.). Statistical analysis was done using the Minitab Statistical Software (Minitab Inc., State College, PA). Descriptive statistics, chi-square analyses, Student t-tests, correlation coefficients, analyses of variance, and discriminant analyses were performed where indicated. Discriminant analysis was used to determine whether we could accurately separate or distinguish between patients who had differing rates of progression and differing institutionalization history.

\section{RESULTS}

\section{Characteristics of Clinic Population}

Most assessed patients (83.5\%) were diagnosed as having a dementia. The remainder were categorized as CIND $(6.7 \%)$, cognitively normal $(5.1 \%)$, amentia/mental retardation $(3.4 \%)$, or diagnosis deferred/no firm diagnosis made (1.3\%). Patients with dementia were significantly older, more cognitively impaired (as measured by the MMS), more functionally impaired (as measured by the MDS), and had a longer duration of symptoms than patients diagnosed as CIND or cognitively normal (Table 1).

Most of those with dementia (89\%) were felt to have Probable (69\%) or Possible (20\%) AD. Pure Vascular Dementia was a rare clinical diagnosis (3\%). Table 2 compares patients with Probable AD, Possible AD, and Vascular Dementia for a number of select patient characteristics. The mean HIS were

Table 1. Comparison between patients with Dementia, with CIND, and those cognitively normal for select characteristics.

\begin{tabular}{lcccl}
\hline & Dementia & CIND & Normal & \\
\hline Number & 462 & 37 & 28 & \\
Female : Male & $277: 185$ & $27: 10$ & $14: 14$ & $\mathrm{p}=0.15$ \\
Education & $10.8(0.14)^{\mathrm{a}}$ & $11.4(0.49)^{\mathrm{a}}$ & $11.6(0.56)^{\mathrm{a}}$ & \\
Age at onset & $67.9(0.45)^{\mathrm{a}}$ & $58.4(2.14)^{\mathrm{b}}$ & $58.4(2.11)^{\mathrm{b}}$ & \\
Duration of symptoms & $4.2(0.13)^{\mathrm{a}}$ & $2.8(0.40)^{\mathrm{h}}$ & $3.3(0.87)^{\mathrm{b}}$ & \\
MDS & $5.4(0.18)^{\mathrm{a}}$ & $2.1(0.29)^{\mathrm{h}}$ & $1.6(0.49)^{\mathrm{b}}$ & \\
MMS score & $17.6(0.35)^{\mathrm{a}}$ & $25.6(0.95)^{\mathrm{b}}$ & $28.4(0.32)^{\mathrm{b}}$ & \\
\hline
\end{tabular}

Mean values with standard error of the mean (S.E.M.). ANOVA (p less than 0.05 ) within one row, values which share a letter are not significantly different. MDS scored 0-17, the higher the score, the more impaired. MMS scored 030 , the lower the score, the more impaired.

Table 2. Comparison between patients with Probable AD, Possible AD, and Vascular Dementia for select characteristics.

\begin{tabular}{|c|c|c|c|}
\hline & $\begin{array}{c}\text { Probable } \\
\text { AD }\end{array}$ & $\begin{array}{c}\text { Possible } \\
\text { AD }\end{array}$ & $\begin{array}{l}\text { Vascular } \\
\text { Dementia }\end{array}$ \\
\hline Number & 319 & 94 & 12 \\
\hline Female : Male & $200: 119$ & $55: 39$ & $\mathrm{p}=0.28$ \\
\hline Age at onset & $68.8(0.54)^{\mathrm{a}}$ & $68.4(0.99)^{\mathrm{s}}$ & $68.2(2.19)^{a}$ \\
\hline Duration of symptoms & $4.4(0.16)^{\mathrm{a}}$ & $3.9(0.28)^{\mathrm{a}}$ & $3.5(0.38)^{\mathrm{a}}$ \\
\hline MDS & $5.4(0.20)^{\mathrm{a}}$ & $6.0(0.42)^{u}$ & $5.8(1.52)^{\circ}$ \\
\hline MMS & $16.7(0.41)^{\mathrm{a}}$ & $18.4(0.76)^{\mathrm{n}}$ & $20.8(0.81)^{\mathrm{b}}$ \\
\hline HIS & $0.4(0.04)^{\mathrm{a}}$ & $2.5(0.31)^{\mathrm{b}}$ & $8.5(0.93)^{c}$ \\
\hline
\end{tabular}

a-c ANOVA ( $\mathrm{p}$ less than 0.05 ) within one row, values which share a letter are not significantly different. HIS scored $0-18$, higher scores are supportive of a diagnosis of Multi-Infarct Dementia. 
significantly higher in those patients with a presumed Vascular Dementia. The higher mean HIS for the Possible AD group was attributed to the inclusion within this group of patients with a presumed mixed vascular and Alzheimer etiology for their dementia.

\section{Probable AD cases}

In patients with Probable $A D$, memory impairment was the earliest (4.55 years mean duration of symptom before first assessment in the Clinic) and most common (99\% prevalence) symptom reported by either the patient or their informant. Difficulties with calculation $(82.75 \%)$, writing $(66.7 \%)$, oral language $(60.2 \%)$, and recognizing people $(53 \%)$ were also common and, in those with these impairments, had been present for approximately two years before their presentation to the Clinic. In this group of patients, social withdrawal (69.9\%) and apathy $(67 \%)$ were the most common behavioral concerns at the time of their first assessment. Functional impairments were also common and correlated with the MMS score (correlation between DS and MMS scores, $r=-0.735$; correlation between MDS and MMS scores, $r=-0.295$ ). Probable AD cases performed significantly worse than normals on all sub-scales of the neuropsychological battery of CERAD. Approximately half of patients had an entirely normal neurological examination aside from their cognitive impairments. The most common abnormal finding was the presence of a Snout reflex (45.8\%). Muscle rigidity was noted in $5.3 \%$ of patients and myoclonus was observed in $1.9 \%$. The most common laboratory abnormalities were an elevated ESR (8\%), low serum B12 (3\%), and a high TSH (3\%). These abnormalities were further assessed and none were felt to be related to the patients' dementia. CT scans were entirely normal in $35 \%$ with the remainder showing varying degrees of ventricular dilatation and cortical atrophy. Both the degree of cortical atrophy and ventricular dilatation were significantly correlated with MMS score (cortical atrophy, $r=-0.324$; ventricular dilatation, $r=-0.341$ ) and the MDS scores (cortical atrophy, $r=0.139$; ventricular dilatation, $r=0.160$ ). In the Probable AD group, $7.2 \%$ of CT scans showed an infarct (compared to $58.3 \%$ for patients with Vascular Dementia and $36.1 \%$ for those with Possible AD/vascular etiology; chi square = 49.58 , p less than 0.0001 ). These infarcts were typically small, single, sub-cortical or located in the left hemisphere. They were not associated with either a history of a stroke or focal neurological findings.

Twenty-five autopsies (62.5\% of all autopsies) showed the neuropathological changes of $\mathrm{AD}$ (one with cortical Lewy bodies). In 2 autopsies (5\% of all autopsies) the apparent cause of the dementia syndrome was vascular. Sensitivity for the clinical diagnosis of Probable or Possible AD was $100 \%$ (25 of 25) with a specificity of $40 \%$ ( 6 out of 15 ). The positive predictive value of a clinical diagnosis of $A D$ was $73.5 \%(25 / 34)$ and the negative predictive value was $100 \%(6 / 6)$. The clinical diagnosis of Probable AD was confirmed in $71.4 \%$ of cases (20/28).

\section{Progression of Probable AD}

Slowly, typically, and rapidly progressive varieties of Probable AD are compared in Table 3. Compared with patients with slowly progressive disease, those with a rapidly progressive variety of $A D$ had higher MDS scores, lower scores on the Boston Naming Test, and lower MMS scores when first seen.
Table 3. Comparison between patients with slowly progressive Probable $\mathrm{AD}$, typically progressive, and those with rapidly progressive Probable AD.

\begin{tabular}{|c|c|c|c|c|}
\hline & Slowly & Typically & Rapidly & Significance \\
\hline Number & 30 & 67 & 38 & \\
\hline Female : Male & $28: 12$ & $41: 26$ & $24: 14$ & $p=0.648$ \\
\hline Age at onset & $68.2(1.4)^{\mathrm{a}}$ & $65.4(1.3)^{a}$ & $68.3(1.1)^{\mathrm{a}}$ & $p=0.167$ \\
\hline Duration of Symptoms & $4.3(0.69)^{a}$ & $4.0(0.27)^{a}$ & $3.7(0.46)^{a}$ & $p=0.714$ \\
\hline MDS & $2.6(0.42)^{\mathrm{a}}$ & $4.0(0.31)^{\mathrm{ub}}$ & $4.4(0.39)^{\mathrm{h}}$ & $p=0.006$ \\
\hline MMS (when first seen) & $22.8(0.74)^{\mathrm{a}}$ & $18.8(0.79)^{\mathrm{b}}$ & $19.6(0.88)^{\mathrm{h}}$ & $p=0.008$ \\
\hline Retrospective Pl & $2.81(4.4)^{4}$ & $3.4(0.29)^{4}$ & $3.7(0.38)^{\mathfrak{a}}$ & $p=0.293$ \\
\hline Prospective PI & $0.42(0.29)^{\mathrm{a}}$ & $2.9(0.12)^{\mathrm{b}}$ & $8.3(0.44)^{c}$ & $\mathrm{p}<0.001$ \\
\hline Family History ${ }^{\prime}$ & $56.7 \%$ & $47.8 \%$ & $55.3 \%$ & $p=0.637$ \\
\hline \multicolumn{5}{|c|}{ Neuropsychology Battery² } \\
\hline - Verbal Fluency & $11.5(0.77)^{\mathrm{a}}$ & $10.4(0.63)^{a}$ & $9.9(1.53)^{a}$ & $p=0.459$ \\
\hline - Construction & $8.5(0.53)^{\mu}$ & $8.4(0.73)^{a}$ & $7.8(0.86)^{a 4}$ & $p=0.834$ \\
\hline - Boston Naming & $12.8(0.46)^{\mathrm{a}}$ & $11.8(0.47)^{\mathrm{ath}}$ & $9.7(1.1)^{\mathrm{h}}$ & $p=0.008$ \\
\hline Extrapyramidal Signs & $10 \%$ & $22.4 \%$ & $26.3 \%$ & $p=0.124$ \\
\hline Months of follow-up & $19.9(2.5)^{\mathrm{ah}}$ & $25.6(1.8)^{\mathrm{h}}$ & $16.0(1.5)^{\mathrm{a}}$ & $p=0.002$ \\
\hline Mortality ${ }^{3}$ & $3.3 \%$ & $16.4 \%$ & $28.9 \%$ & $p=0.008$ \\
\hline Institutionalization ${ }^{3}$ & $16.7 \%$ & $28.4 \%$ & $55.3 \%$ & $p=0.002$ \\
\hline
\end{tabular}

a-b ANOVA ( $p$ less than 0.05 ) within one row, values which share a letter are not significantly different.

' positive family history was defined as at least one first degree relative with dementia.

2 Neuropsychology battery of CERAD:Number tested was 25 in the slowly progressive (mean MMS score of those tested was 24.12, S.E.M. 0.49), 24 in the typically progressive (MMS score 23.4, SEM 0.58), and 11 in the rapidly progressive (MMS 20.9 , SEM 1.8) groups respectively.

${ }^{3}$ rate during follow-up.

Patients with rapidly progressive disease had a worse prognosis than the other two varieties. When first seen there were no statistically significant differences between the typically and rapidly progressive varieties. We performed various discriminant analyses to find which combination of baseline characteristics best distinguished those patients with slowly progressive disease. With our best model (incorporating the MMS, MDS, Boston Naming Test, presence of extrapyramidal signs, and the patient's age) we were able to correctly classify $66.7 \%$ of cases. A model utilizing only the MMS score and the MDS was nearly as successful (correctly classified $63.7 \%$ ). After eliminating all slowly progressive cases, we next performed various discriminant analyses to determine which baseline characteristics best distinguished between rapidly and typically progressive cases. With our best model (incorporating the MMS, MDS, Boston Naming Test, presence of extrapyramidal signs, and the patient's age) we were able to correctly classify $65.7 \%$ of cases.

\section{Five-year Mortality and Institutionalization}

Figure 1 and 2 show five-year institutionalization and mortality rates respectively. At presentation to the Clinic, $16 \%$ of patients were already institutionalized. The overall five-year institutionalization rate was $79 \%$. Nearly forty percent $(37.1 \%)$ of patients with Probable AD had died within five years of being seen in the Clinic, 2.5 times the expected rate. When compared no significant differences between those who expired and those who survived were found with respect to a number of characteristics including age of onset, duration of symptoms, MMS score 
or rate of institutionalization. There was a higher prevalence of apathy $(\mathrm{p}=0.03)$ in individuals who had died.

There were significant differences between individuals requiring early institutionalization (at or within 1 year of being seen in the Clinic), late institutionalization (between 1 and 5 years of follow-up) and community residents. Individuals with early institutionalization were older $(\mathrm{p}=0.04)$, more cognitively impaired ( $\mathrm{p}=0.04)$, and more functionally impaired ( $\mathrm{p}=$ $0.006)$. Individuals with late institutionalization had a more

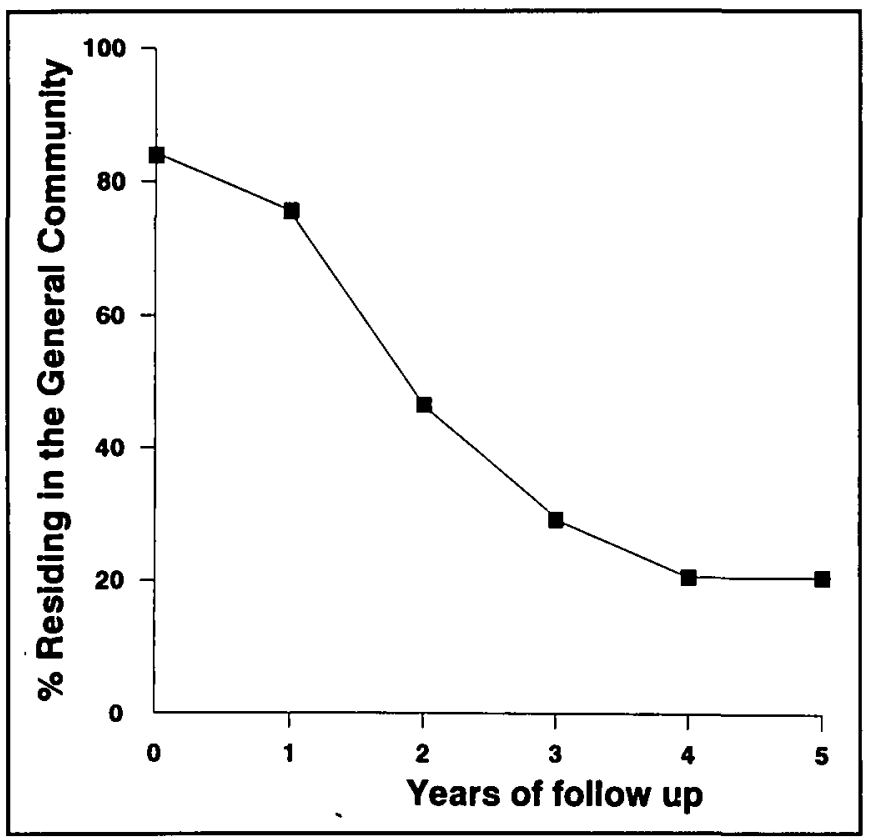

Figure 1: Rate of institutionalization for Probable AD patients followed for five years.

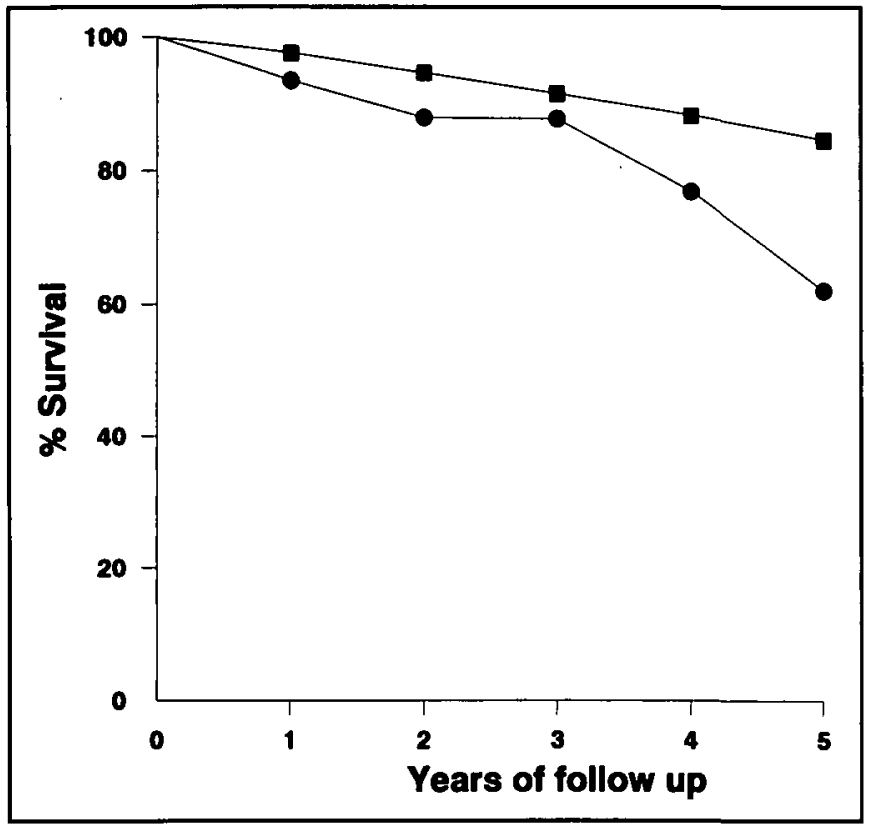

Figure 2: Observed (O) and expected ${ }^{47}(\mathbf{\square})$ survival rates for Probable $A D$ patients for five years. rapid disease progression (as measured by the prospective $\mathrm{PI}$ ) than community subjects $(\mathrm{p}=0.02)$. There was a trend for those institutionalized to be more likely to be unmarried $(p=0.06)$. We did not find any significant differences between the groups in the prevalence of behavioral problems and specific functional concerns, such as incontinence, at the time of presentation to the Clinic. By the time of institutional admission, most patients were severely demented (57\% scored 10 or less on their last MMS before institutionalization). The two most successful discriminant analysis models for predicting early institutionalization both correctly classified $79.3 \%$ of cases. One model utilized MMS score and marital status while the second used age and marital status. After eliminating the early institutionalization cases, we performed various discriminant analyses to determine which baseline characteristics best distinguished between those not institutionalized and those institutionalized by the end of five years of follow-up. The best model accurately predicted $65.9 \%$ of cases and utilized age and MDS.

\section{Comparison of Clinic patients and the description of Demented individuals derived from the CSHA}

At the time of referral, Clinic patients tended to be younger, were more likely to be community residents, and appeared to have a milder degree of dementia. They were more likely to be felt to be suffering from AD (Table 4).

\section{Discussion}

When compared to published reports of other ambulatory care clinics for the assessment and management of dementia, we noted more similarities than differences. Most referred patients were found to have a dementia. AD was the most common clinical and pathological diagnosis. As previously reported, we found that routine laboratory studies were generally unremarkable for patients with a diagnosis of probable AD. ${ }^{4.50}$ The presence

Table 4. Comparison of patients seen in the Dementia Research Clinic and description of subjects with dementia from the Canadian Study of Health and Aging (CSHA).

\begin{tabular}{|c|c|c|}
\hline & $\begin{array}{c}\text { Dementia } \\
\text { Research Clinic }\end{array}$ & CSHA \\
\hline Female/Male ratio & $1.5 / 1.0$ & $2.1 / 1.0^{1}$ \\
\hline \multicolumn{3}{|l|}{ Percentage of cases } \\
\hline Less than 65 years of age & $24 \%$ & N/A \\
\hline $65-74$ years of age & $35 \%$ & $18 \% 1$ \\
\hline $75-84$ years of age & $36 \%$ & $44 \% 1$ \\
\hline More than 84 years of age & $6 \%$ & $36 \% 1$ \\
\hline Long-term Care Institution & $17 \%^{2}$ & $59 \% \%^{3}$ \\
\hline Mean MMS score & 17.6 & $12.9^{4}$ \\
\hline Duration of Cognitive Symptoms & 4.2 & $3.8^{4}$ \\
\hline \multicolumn{3}{|l|}{ Percentage of Dementia cases } \\
\hline Alzheimer's Disease & $86 \%$ & $64 \%^{\prime}$ \\
\hline Vascular Dementia & $3 \%$ & $19 \%^{1}$ \\
\hline Other Forms & $11 \%$ & $17 \% 1$ \\
\hline \multicolumn{3}{|c|}{ 'National data, Canadian Study of Health and Aging. } \\
\hline \multicolumn{3}{|c|}{2 When first seen in the Clinic. } \\
\hline \multicolumn{3}{|c|}{${ }^{3}$ Prairies data, Canadian Study of Health and Aging. } \\
\hline${ }^{4}$ Mean value for all dementia case & & \\
\hline
\end{tabular}


of a single infarct on a CT scan does not preclude the clinical diagnosis of Probable AD in individuals with no neurological evidence of a stroke and where no relationship between the infarct and dementia can be made. ${ }^{51}$ To confirm the veracity of the clinical diagnosis, neuropathological confirmation is still required. Clinicopathological studies have shown varying figures for the sensitivity $(62.5-100 \%)$, specificity $(41-73 \%)$, positive predictive value $(46-95 \%)$, and negative predictive value $(70-100 \%)$ of a clinical diagnosis of $A D .^{9.52-60}$ For these numbers to be interpretable, knowledge of the prevalence of the various types or causes of dementia in the studied populations is needed. The prevalence of neuropathologically confirmed AD in the studied populations range from $22 \%$ to $91 \% .^{9,52-60}$ In our Clinic, the prevalence of $\mathrm{AD}$ in our autopsied cases was $62.5 \%$. Our clinical diagnosis of AD carried a high sensitivity, a low specificity, and an intermediate positive predictive value. In certain cases, we found it difficult to distinguish Alzheimer's disease from other forms of primary neurodegenerative dementia. Our results underscore the need to develop reliable criteria verified by neuropathology for the diagnosis of other types of primary neurodegenerative processes leading to the dementia syndrome.

The rate of progression, as measured by the MMS score, was found to be variable. When contrasted to patients with a slowly progressive variant, rapidly progressive patients were found to have a lower initial MMS score. Other researchers have found that the rate of change of the MMS score varies with the degree of cognitive impairment. 11,12 The annual rate of decline is apparently less at higher and lower MMS scores with the most rapid declines occurring in the middle ranges. In our population, patients with higher MMS scores (i.e., 20 points or higher) appeared to have slower rates of decline than those with scores in the 10 to 20 range. We cannot comment on the lower part of the scale as we had few patients presenting to the clinic with low MMS scores (i.e., less than 10). Other significant differences between the groups were noted. The Boston Naming Test appeared to distinguish the rapidly progressive from the slowly progressive group. Boller et al., has reported that performance in verbal tests, for example the Boston Naming Test, was the best predictor of rapid declines in MMS scores in patients with Probable AD. ${ }^{61}$ Huff et al., also reported that verbal skills (i.e., impaired object naming) were strongly associated with more rapid progression. ${ }^{62}$ The prognosis was influenced by the rate of progression with the rapidly progressive group having the highest mortality and institutionalization rates. The baseline characteristics we examined were at best only modestly successful in predicting rates of decline. It must be noted that a number of patient characteristics reported to be associated with the rate of progression were either not examined (e.g., certain EEG characteristics), arguably were not collected with sufficient rigour (e.g., behavioral concerns), and significant associations may have been missed because of inadequate study power. The outcome measure itself - the MMS score - is not an ideal tool for monitoring disease progression. ${ }^{10,23}$ The measurement and prediction of disease progression is vital for both patient care and the interpretation of clinical dementia research such as drug trials.

Our Probable AD group had an increased mortality rate. We could not identify any statistically significant markers for this outcome other than a higher prevalence of apathy. Institutionalization was an even more common adverse outcome within five years of presentation to the Clinic. A number of risk factors for this outcome were evident such as an older age, greater cognitive impairment, more rapid progression, and greater functional impairments. The importance of noncognitive factors cannot be minimized in predicting institutionalization. We found that simple demographic and social factors such as the patient's age and marital status were strong predictors for early institutionalization. Unfortunately we collected little standardized information on the characteristics of our family care-givers. Comprehensive, integrated assessment of referred patients and their care-givers is needed to better understand the relative importance of various factors in the process of instititutionalization and in devising interventions aimed at supporting dementia sufferers in the community.

Compared to the recently completed prevalence study, ${ }^{36}$ Clinic patients appeared to be different than the "typical" dementia sufferer. At presentation, Clinic patients were younger. While the CSHA was limited to subjects 65 years of age or greater, it is known that dementia is clearly an age-associated diagnosis, becoming more common with increasing age. Just within the 65 and over age range, more of the Clinic patients were 65 to 74 years of age ( $45 \%$ versus $18 \%$ ) and fewer were 85 and over ( $8 \%$ versus $36 \%$ ). They also appeared to have a milder degree of dementia as measured by the MMS and were more likely to be residing in the general community - also presumably a reflection of their milder severity. This premise is supported by the observation that the mean MMS score for CSHA subjects residing in the general community was $18.2,{ }^{49}$ a value very close to our average MMS of 17.6 at the time of presentation. The differing ages, place of residency, and dementia severity do not necessarily indicate that our Clinic population was non-representative of dementia subjects in our community. They were arguably just being seen earlier in the course of their illness. Undermining this premise was the equivalent duration of cognitive symptoms. The differing proportions of the specific causes of dementia were also of concern. For example, the diagnosis of vascular dementia was rarely made in our Clinic presumably because few patients with vascular dementia were referred. At autopsy only $5 \%$ of our cases were felt to be suffering from a vascular dementia. We feel that our Clinic (and presumably other clinics) sees a selected, pre-screened population which is non-representative of the dementia population as a whole.

A number of conclusions appear supportable from our data. Patients seen in a Canadian Dementia Clinic were very similar to Clinic patients seen in the United States and elsewhere. AD was the most common clinical and clinicopathological diagnosis. The rate of progression of $\mathrm{AD}$ varied markedly among patients. While certain characteristics were associated with rates of progression, there is an obvious need for further work to better define prognostic features. Probable AD cases had a higher than expected mortality rate and a high risk for institutionalization. In addition to clinical features, demographic and social factors are critical for the understanding of the phenomenon of institutionalization. While reports from selected populations such as ours can provide important insights, one must be cautious in extrapolating these results to the dementia population as a whole.

\section{ACKNOWLEDGEMENTS}

Dr. D. Hogan is supported by the Brenda Strafford Chair in Geriatrics. Dr. Thierer was supported by a Fellowship granted by the Alberta-NWT Command, the Royal Canadian Legion. The authors 
would like to thank the following individuals for their contributions to the clinic: Dr. Marian Hill, Dr. Gregor Jason, Pam Mueller R.N., Gina Rohs R.N., Michelle Hynds, Cheryl Field, the patients and their caregivers.

The Canadian Study of Health and Aging was funded by the Seniors Independence Research Program, administered by the National Health Research and Development Program of Health and Welfare Canada. The study was coordinated through the University of Ottawa and the federal government's Laboratory Centre for Disease Control.

\section{REFERENCES}

I. Verhey FR, Jolles J, Ponds RW, et al. Diagnosing dementia- a comparison between a monodisciplinary and a multidisiciplinary approach. J Neuropsychiatry Clin Neurosci 1993; 5: 78-85.

2. Thal LJ, Grundman M, Klauber MR. Dementia: Characteristics of a referral population and factors associated with progression. Neurology 1988; 38: 1083-1090.

3. Erkinjuntti T, Sulkava R, Kovanen J, Palo J. Suspected dementia: evaluation of 323 consecutive referrals. Acta Neurol Scand 1987; 76: 359-364.

4. Brodaty $\mathrm{H}$. Low diagnostic yield in a memory disorders clinic. Int Psychogeriatr 1990; 2: 149-159.

5. Larson EB, Reifler BV, Featherstone HJ, English DR. Dementia in elderly outpatients: a prospective study. Ann Intern Med 1984; 100: 417-423

6. Van der Cammen TJM, Simpson JM, Fraser RM, Preker AS, Exton-Smith AN. The Memory Clinic: a new approach to the detection of dementia. Br J Psychiatry 1987; 150: 359-364.

7. Bayer AJ, Pathy MSJ, Twining C. The Memory Clinic: a new approach to the detection of early dementia. Drugs 1987; 33: 8489.

8. Reding MJ, Haycox J, Wigforss K, Brush D, Blass JP. Follow up of patients referred to a dementia service. J Am Geriatr Soc 1984; 32: $265-268$.

9. Brayne C. Clinicopathological studies of the dementias from an epidemiological viewpoint. Br J Psychiatry 1993; 162: 439-446.

10. Galasko D, Corey-Bloom J, Thal LJ. Monitoring progression in Alzheimer's disease. J Am Geriatr Soc 1991; 39: 932-941.

11. Morris JC, Edland S, Clark C, et al. The Consortium to Establish a Registry for Alzheimer's Disease (CERAD) - Part IV: Rates of cognitive change in the longitudinal assessment of probable AD. Neurology 1993; 43: 2457-2465.

12. Brooks JO, Kraemer HC, Tanke ED, Yeasavage JA. The methodology of studying decline in Alzheimer's disease. J Am Geriatr Soc 1993; 41: 623-628.

13. Mayeux R, Stern Y, Spanton S. Heterogeneity in dementia of the Alzheimer's type: evidence of subgroups. Neurology 1985; 35: 453-46I.

14. Mortimer JA, Ebbitt B, Jun SP, Finch MD. Predictors of cognitive and functional progression in patients with Probable Alzheimer's disease. Neurology 1992; 42: 1689-1696.

15. Burns A, Levy R. Clinical diversity in late onset Alzheimer's Disease. Oxford: Oxford University Press, 1992.

16. Forstl H, Resthorn C, Geiger-Kabisch C, et al. Psychotic features and the course of Alzheimer's disease-relationship to cognitive, electroencephalographic and computerized tomography findings. Acta Psychiatr Scand 1993; 87: 395-399.

17. Kuskowski MA, Mortimer JA, Morley GK, et al. Rate of cognitive decline in Alzheimer's disease is associated with alpha EEG power. Biol Psychiatry 1993; 33: 659-662.

18. Stern Y, Folstein M, Albert M, et al. Multicenter study of predictors of disease course in Alzheimer's disease (the "predictors study") I: Study design, cohort description and intersite comparison. Alzheimer Dis Assoc Disord 1993; 7(1): 3-21.

19. Richards M, Folstein M, Albert M, et al. Multicenter study of predictors of disease course in Alzheimer's disease (the "predictors study"). II: Neurological, psychiatric and demographic influences on baseline measurements of disease severity. Alzheimer Dis Assoc Disord 1993; 7(1): 22-32.

20. Yesavage JA, Brooks JO, Taylor J, Tinklenburg J. Development of aphasia, apraxia, and agnosia and decline in Alzheimer's disease. Am J Psychiatry 1993; 150: 742-747.
21. Lucca U, Comelli M, Tettamanti $M$, et al. Rate of progression and prognostic factors in Alzheimer's disease - a prospective study. J Am Geriatr Soc 1993; 41: 45-49.

22. Mann UM, Mohr E, Gearing M, Chase TN. Heterogeneity in Alzheimer's disease-progression rate segregated by distinct neuropsychological and cerebral metabolic profiles. J Neurol Neurosurg Psychiatry 1993; 55: 956-959.

23. Tombaugh TN, McIntyre NJ. The mini-mental state examination: a comprehensive review. J Am Geriatr Soc 1992; 40(9): 922-935.

24. Barclay LL, Zemcov A, Blass JP, McDowell FH. Factors associated with duration of survival in Alzheimer's disease. Biol Psychiatry 1985; 20: 86-93.

25. Barclay LL, Zemcov A, Blass JP, Sansone J. Survival in Alzheimer's disease and vascular dementias. Neurology 1985: 35: 834-840.

26. Diesfeldt HFA, van Houte LR, Moerkens RM. Duration of survival in senile dementia. Acta Psychiatr Scand 1986; 73: 366-371.

27. Mölsä PK, Marttila RJ, Rinne UK. Survival and cause of death in Alzheimer's disease and multi-infarct dementia. Acta Neurol Scand 1986; 74: 103-107.

28. Martin DC, Miller JK. Kapoor W, Arena VC, Boller F. A controlled study of survival with dementia. Arch Neurol 1987; 44: 11221126.

29. Hier DB, Warach JD, Gorelick PB, Thomas J. Predictors of survival in clinically diagnosed Alzheimer's disease and multiinfarct dementia. Arch Neurol 1989; 46: 1213-1216.

30. Robinson JR. The natural history of mental disorder in old age: a long-term study. Br J Psychiatry 1989; 154: 783-789.

31. Walsh JS, Welch GH, Larson EB. Survival of outpatients with Alzheimer-type dementia. Ann Intern Med 1990; 113: 429-434.

32. Kazniak AW, Fox J, Gandell DL, et al. Predictors of mortality in presenile and senile dementia. Ann Neurol 1978; 3: 246-252.

33. Volicer BJ, Hurley A, Fabiszewski KJ, et al. Predicting short-term survival for patients with advanced Alzheimer's disease. J Am Geriatr Soc 1993; 41: 535-540.

34. Drachman DA, O'Donnell BF, Lew RA, Swearer JM. The prognosis in Alzheimer's disease. Arch Neurol 1990; 47: 851-856.

35. Brodaty $\mathrm{H}$, McGilchrist $\mathrm{C}$, Harris L, Peters KE. Time until institutionalization and death in patients with dementia. Arch Neurol 1993; 50: 643-650.

36. Canadian Study of Health and Aging. The Canadian study of health and aging: study methods and prevalence of dementia. Can Med Assoc J 1994; 150: 899-913.

37. Folstein MF, Folstein SE, McHugh PR. "Mini-mental state" A practical method for grading the cognitive state of patients for the clinician. J Psychiatr Res 1975; 12: 189-198.

38. Blessed GL, Tomlinson BE, Roth $M$. The association between quantitative measures of dementia and of senile change in the cerebral grey matter of elderly subjects. Br J Psychiatry 1968; 114: 797-811.

39. Morris JC, Heyman A, Mohs RC, et al. The Consortium to Establish a Registry for Alzheimer's Disease (CERAD). Part I: Clinical and neuropsychological assessment of Alzheimer's disease. Neurology 1989; 39: 1159-1165.

40. Hachinski VC, Iliff LD, Zilhka E, et al. Cerebral blood flow in dementia. Arch Neurol 1975: 8: 141-151.

41. Hendrie HC, Hall KS, Brittain HM, et al. The CAMDEX. J Am Geriatr Soc 1988; 36: 402-408.

42. Morris JC, Mohs RC, Roger H, Fillenbaum G, Heyman A. Consortium to Establish a Registry for Alzheimer's Disease (CERAD) Clinical and Neuropsychological Assessment of Alzheimer's Disease. Psychopharmacol Bull 1988; 24: 641-644.

43. LeMay M, Stafford JL, Sandor T, et al. Statistical assessment of perceptual CT scan rating inpatients with Alzheimer type dementia. J Comput Assist Tomogr 1986; 10:802-809.

44. Diagnostic and Statistical Manual of Mental Disorders. 3rd ed. Washington, DC: American Psychiatric Association, 1980.

45. Diagnostic and statistical manual of mental disorders (revised). 3rd ed. Washington; DC: American Psychiatric Association, 1987.

46. McKhann G, Drachman D, Folstein M, et al. Clinical diagnosis of Alzheimer's disease: Report of the NINCDS-ADRDA Work Group under the auspices of Department of Health and Human Services task force on Alzheimer's disease. Neurology 1984; 34 : 939-944. 
47. Life tables, Canada and Provinces 1985-1987. Statistics Canada Health Reports, 1990: 49.

48. Teng EL. The Modified Mini-Mental State (3MS) Examination. J Clin Psychiatr 1987; 48: 314-318.

49. Canadian Study of Health and Aging, personal communication.

50. Larson EB, Reifler BV, Sumi SM. Diagnostic tests in the evaluation of dementia. Arch Intern Med 1986; 146: 1917-1922.

51. Roman GG, Tatemichi TK, Erkinjuntti T, et al. Vascular dementia: diagnostic criteria for research studies. Neurology 1993; 43: 250-260.

52. Boller F, Lopez OL, Moossy J. Diagnosis of dementia: clinicopathologic correlations. Neurology 1989; 39: 76-79.

53. Sulkava R, Haltia M, Paetau A, Wikstrom J, Palo J. Accuracy of clinical diagnosis in primary degenerative dementia: correlation with neuropathological findings. J Neurol Neurosurg Psychiatry 1983; 46: 9-13.

54. Mölsä PK, Paljärvi L, Rinne JO, Rinne UK, Säkö E. Validity of clinical diagnosis in dementia: a prospective clinicopathological study. J Neurol Neurosurg Psychiatry 1985; 48: 1085-1090.
55. Wade JP, Mirsen TR, Hachinski VC, et al. The clinical diagnosis of Alzheimer's disease. Arch Neurol 1987; 44: 24-29.

56. Homer AC, Honavar M, Lantos PL, et al. Diagnosing dementia: do we get it right? Br Med J 1988; 297: 894-896.

57. Risse SC, Raskind MA, Nochlin D, et al. Neuropathological findings in patients with clinical diagnosis of Probable Alzheimer's Disease. Am J Psychiatry 1990; 147: 168-172.

58. Thal L, Galasko D, Katzman R, et al. Patients clinically assessed at an Alzheimer's center generally have Alzheimer's pathology. Neurology 1991; 41: 323.(Abstract)

59. Burns A, Luthert P, Levy R, Jacoby R, Lantos P. Accuracy of clinical diagnosis of Alzheimer's disease. Br Med J 1990; 301: 1026.

60. Gilleard CJ, Kellet JM, Coles JA, et al. The St. George's dementia bed investigation study: a comparison of clinical and pathological diagnosis. Acta Psychiatr Scand 1992; 85: 264-269.

61. Boller F, Becker JT, Holland AL, et al. Predictors of decline in Alzheimer's disease. Cortex 1991; 27: 9-17.

62. Huff FJ, Belle SH, Shim YK, Ganguli M, Boller F. Prevalence and prognostic value of neurologic abnormalities in Alzheimer's disease. Dementia 1990; 1: 32-40. 